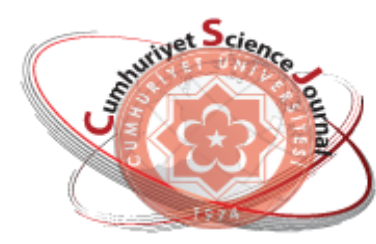

e-ISSN: 2587-246X

ISSN: 2587-2680

\section{Cumburiyet Scionce Journal}

esJ

Cumhuriyet Sci. J., Vol.38-4 (2017) 639-646

\author{
Küçük Aksu Çayı Taşkın Frekans Analizi \\ Tahsin BAYKAL ${ }^{1}$, Özlem TERZí2*

 \\ ${ }^{2}$ Süleyman Demirel Üniversitesi, Teknoloji Fakültesi, İnşaat Mühendisliği Bölümü, 32260 Isparta / TÜRKIYYE \\ Received: 20.04.2017; Accepted: 13.07.2017 \\ http://dx.doi.org/10.17776/csj.348907
}

\begin{abstract}
Özet: Taşkın debilerinin tahmini, taşkın kontrolünün planlanması ve projelendirilmesinde, taşkın zararlarının azaltılmasında ve su yapılarının tasarımında oldukça önemlidir. Bu çalışmada, taşkın tekerrür debilerinin tahmini için üç parametreli log-normal, Gumbel, Pearson Tip III ve Log- Pearson Tip III olasılık dağılımları kullanılmıştır. En uygun olasılık dağılımını belirlemek için Kolmogorov-Smirnov testi yapılmıştır ve dağılım grafikleri elde edilmiştir. Kolmogorov-Smirnov testi ve dağılım grafiklerine göre taşkın tekerrür debilerinin tahmininde en uygun olasılık dağılımının Log-Pearson Tip III olduğu görülmüştür. Log-Pearson Tip III dağılımında, 100 yıllık taşkın debisi $236,10 \mathrm{~m}^{3} / \mathrm{sn}$ olarak belirlenmiştir.
\end{abstract}

Anahtar Kelimeler: Taşkın tekerrür debisi, olasılık dağılımları, Kolmogorov-Smirnov testi, Küçük Aksu Çayı

\title{
Flood Frequency Analysis of Kucuk Aksu River
}

\begin{abstract}
The determination of flood flows is very important in flood control planning and projecting, reducing of flood damages and designing of water structures. In this study, three-parameter log-normal, Gumbel, Pearson Type III and Log-Pearson Type III probability distributions were used to determine flood recurrences flows. To determine the optimal probability distribution, the Kolmogorov-Smirnov test was used and distribution graphics were obtained. According to the Kolmogorov-Smirnov test and the distribution graphics, it was shown that the most suitable probability distribution is Log-Pearson Type III in determining flood recurrence flows. In Log-Pearson Type III, 100 years flood flow was determined as $236,10 \mathrm{~m}^{3} / \mathrm{s}$.
\end{abstract}

Keywords: Flood recurrence flow, probability distributions, Kolmogorov-Smirnov test, Küçük Aksu Stream

\section{GíRiş}

Meteorolojik olayların yanısıra, Türkiye gibi gelişmekte olan ülkelerde, sanayileşme ve sektör çeşitliliğinin beraberinde getirdiği kentleşme, akarsu havzalarında insan faaliyetinin çeşitliliği ve yoğunluğu da büyük ölçüde taşkın olaylarını arttırmaktadır. Taşkınlar nedeniyle havzadaki hidrolojik denge bozulmakta ve büyük miktarda can ve mal kayıpları yaşanmaktadır [1].

Tekerrür periyotlarına bağlı olarak taşkın debilerinin tahmini, taşkın kontrolünün planlama ve projelendirilmesinde, taşkın zararlarının azaltılmasinda ve su yapılarının tasarımında oldukça önemlidir. Akım gözlem istasyonlarından elde edilen akım değerlerinden yola çıkarak gelmesi muhtemel taşkının debileri istatistiksel yöntemler kullanılarak tahmin edilebilmektedir. Gelebilecek taşkın debileri önceden tahmin edilerek taşkın zararlarının en aza indirgenmesi için gerekli önlemler alınabilir ve su yapıları tasarlanabilir [2].

\footnotetext{
* Corresponding author. Email address: ozlemterzi@sdu.edu.tr 
Hidrolojik frekans analizlerinde verilen bir dağılımın verilere uygunluğu kesin olarak bilinmemektedir. Bunun için veriler çeşitli olasılık dağılımları ile denenir ve bu dağılımların arkasından veriye en uygun dağılımın ve yapılan tahminlerin ne kadar doğru olduğunun belirlenmesi gerekmektedir [3].

Taşkın debilerinin belirlenmesinde sıklıkla LogNormal III, Log-Pearson Tip III, Gamma II, Gamma III ve Gumbel dağılımları kullanılmaktadır. En uygun dağılımın belirlenmesinde ise Ki-Kare ve KolmogrovSimirnov gibi uygunluk testlerinden yararlanılmaktadır. Aşı vd. (2004) Gediz havzasındaki bazı akarsuların belirli tekerrür sürelerinde gelebilecek y1llik toplam akım miktarlarının tahmini için normal, Log-Normal II, Log-Normal III, Gamma II, Log-Pearson Tip III ve Gumbel dağılımları ile modeller geliştirmişlerdir. Modellerin uygunluklarını Kolmogrov-Simirnov testi ile kontrol etmişlerdir. Kolmogrov-Simirnov testine göre en uygun dağılımın Log-Pearson Tip III dağılımı olduğunu saptamışlardır [4]. Anlı (2006) Giresun Aksu Havzası maksimum akım frekans modellemesi için normal, Log-Normal, üç parametreli logaritmik normal, Gumbel, Gamma, Pearson Tip III, Log-Pearson Tip III, Weibull, üç parametreli Weibull ve Log-Lojistik dağılımlarını kullanmış ve bu dağılımların uygunluğunu KolmogorovSmirnov testi ile sınamıştır. Sınama sonuçlarına göre 1, 6, 7 ve 8. aylar için Log-Pearson Tip III, 3 ve 5. aylar için üç parametreli log- normal, 4 ve 9. aylar için Pearson Tip III, 10 ve 12. aylar için üç parametreli Weibull, 2 ve 11. aylar için de LogLojistik dağılımlarının kullanılabilirliğini belirlemiştir [3]. Büyükkaracığan ve Kahya (2009) Konya Havzası'nda bulunan 13 akarsuya ait yıllık pik akım serilerine bağımlılık testleri uygulamışlardır. Uygulanan testlerin sonucuna göre 13 akarsuyun sadece bir tanesinin bağımlı bir karakter göstermediğini belirlemişlerdir. Yıllık pik akımların birinci seri otokorelasyon katsayıları ile havzadaki su tutma kapasitesi arasında dikkat

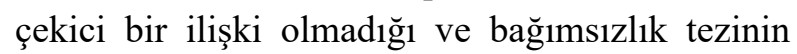
havzada bulunan akarsular için geçerli olduğu sonucuna varmışlardır. Ayrıca, 12 istasyona ait yıllık pik akım serilerine iki ve üç parametreli Log-Normal, Gumbel, Pearson Tip III, LogPearson Tip III, Log-Boughton ve Log-Lojistik uygulayarak en uygun olasılık dağılım modelini belirlemişlerdir. En uygun modeli seçmek için KiKare ve Kolmogorov-Smirnov uygunluk testlerini kullanmışlardır. Uygunluk testleri sonucunda Log-Pearson Tip III dağılımının diğerlerine göre uygun sonuçlar verdiğini gözlemlemişlerdir [5]. Saka vd. (2013) Doğu Karadeniz Havzası'nda bulunan 23 adet akım gözlem istasyonuna (AGI) ait yıllık maksimum akım verilerine Log-Normal, Gumbel, Log-Pearson Tip III dağılımlarını uygulayarak, bu dağılımların uygunluğunu KiKare ve Kolmogorov-Smirnov testleri ile kontrol etmişlerdir. Yaptıkları uygunluk testleri sonucunda en iyi dağ 11 ımın Log-Normal olduğunu, Gumbel dağılımının da verilere iyi uyum sağladığını, Log-Pearson Tip III dağılımının ise uygun olmadığını belirlemişlerdir [6]. Yüksek vd. (2013) Doğu Karadeniz Bölgesi’nde bulunan 45 adet AGI'ye ait yıllık en büyük debi değerleri ile aynı bölgede bulunan 9 adet meteoroloji istasyonunda ölçülen yıllık en büyük yağış şiddetlerine uyan dağılımları incelemişlerdir. Debi ve yağış verilerine Gumbel, Log-Normal, Log-Pearson Tip III dağılımlarını uygulamışlardır. En uygun dağılımı belirlemek için Ki-Kare ve olasıllk çizgi korelasyon testlerini uygulamışlardır. Yapılan testler sonucunda, LogNormal dağılımının hem debi hem de yağış verileri için en uygun dağılım olduğunu belirlemişlerdir [7].

Bu çalışmanın amacı; Küçük Aksu Çayı üzerinde yapılacak su yapılarının güvenirliğini artırmak, taşkın kontrolünü sağlamak ve olası bir taşkın durumunda zararı minimize etmek için farklı tekerrür periyotlarında meydana gelebilecek taşkın debilerini tahmin etmektir.

\section{TAŞKIN FREKANS ANALIZLERİ}

Seçilen bir $T$ dönüş aralığına göre dönegelme yılının en büyük debisi olarak tanımlanan taşkın debileri rastgele bir değişken olduğundan istatistiksel analizlerinin yapılması gerekmektedir. Seçilen bir $T$ dönüş aralığı, akarsu kesitinde $x_{t}$ 
taşkın debisi değerinin iki kez aşılması için geçen süreyi ifade etmektedir.

$x_{t}$ debisinin aşılma olasıllı̆ $1 \mathrm{p}_{\mathrm{T}}$ ile ifade edilirse, art arda gelen yıllardaki taşkın debilerinin bir birinden bağımsız olduğu kabul edilir ve $x_{t}$ debisinin iki kez aşılması için geçen süre $i$ yıl olma olasılığı denklem 1'deki şekliyle hesaplanır.

$$
\left(1-p_{T}\right)^{i-1} p_{t}
$$

Dönüş aralığı $(T)$ denklem 2'den elde edilir.

$$
\mathrm{T}=\sum_{\mathrm{i}=1}^{\infty}\left(1-\mathrm{p}_{\mathrm{T}}\right)^{\mathrm{i}-1} \mathrm{p}_{\mathrm{T}}=\frac{1}{\mathrm{p}_{\mathrm{T}}}
$$

$\mathrm{p}_{\mathrm{T}}=\mathrm{P}\left[\mathrm{X}>\mathrm{x}_{\mathrm{T}}\right]=1-\mathrm{P}\left[\mathrm{X} \leq \mathrm{x}_{\mathrm{T}}\right]=1-\mathrm{F}_{(\mathrm{x})_{\mathrm{T}}}$ olmasından dolayı, $x_{t}$ debisinin $\mathrm{F}_{\mathrm{x}}$ eklenik dağılım fonksiyonu $\left(\mathrm{F}_{(\mathrm{x})_{\mathrm{T}}}\right)$ denklem 3'den hesaplanır [8].

$$
\mathrm{F}_{(\mathrm{x})_{\mathrm{T}}}=1-\frac{1}{\mathrm{~T}}
$$

\section{1. Üç Parametreli Log-Normal Dağılım}

Birçok durumda $x$ rastgele değişkeninin logaritmalarını almakla, değişken normal dağılıma pek uymamaktadır. Ancak $\mathrm{x}_{0}$ gibi bir alt sinır değeri çıarıldıktan sonra logaritmik dönüşüm yapıldığında değişken normal dağılıma uyabilmektedir (denklem 4).

$$
y=\ln \left(x-x_{0}\right)
$$

Debiyi hesaplamak için kullanılan formül denklem 5'de verilmiştir.

$Q=x_{o r t}+k \sqrt{\left(\frac{\sum X^{2}}{N}-x_{o r t}^{2}\right) \times\left(\frac{N}{N-1}\right)}$

$\mathrm{Bu}$ formüldeki $k$ frekans faktörü denklem 6 'da verilmiştir.

$$
k=\frac{e^{(\sqrt{a} \times z-a / 2)}-1}{f}
$$

Frekans faktörü denklemindeki a ve f katsayıları ve diğer parametreler denklem 7, 8, 9 ve 10 'da ve çarpıklık katsayısı denklem 11'de gösterilmiştir [9].

$$
\begin{gathered}
a=\ln \left(z^{2}+1\right) \\
f=\frac{\left(1-d^{(2 / 3)}\right)}{\left.d^{(1 / 3}\right)} \\
d=\frac{-c+\sqrt{c^{2}+4}}{2} \\
c=\frac{\left(\frac{\sum x^{3}}{N}\right)+2 x_{o r t}^{3}-3 x_{o r t} \times\left(\frac{\sum x^{2}}{N}\right)}{\left(\frac{\sum x^{2}}{N}-x_{o r t}^{2}\right)^{1,5}} \\
C_{S}=\frac{N \times \sum_{i=1}^{n}\left(X_{i}-\bar{X}\right)^{3}}{(N-1) \times(N-2) \times S_{n}^{3}}
\end{gathered}
$$

\subsection{Gumbel Dağılımı}

Gumbel 1958 yılında tekrarlanan örneklemdeki en büyük ve en küçük değerlerin dağılımlarını göz önüne alarak Gumbel (ekstrem) değerler teorisini önermiştir. $\mathrm{Bu}$ dağılımda $x$ değerine eşit veya daha büyük taşkının olma ihtimali (p) denklem 12 'de verilmiştir.

$$
p=1-e^{-e^{-y}}
$$

Burada, $y$ indirgenmiş değişkendir ve denklem 13 ile gösterilmiştir.

$$
y=a\left(x-x_{0}\right)
$$

Bu denklemde; $x, p$ olma ihtimaline sahip taşkın değeri, $a$ sabit bir değer, $x_{0}$ ise dağılımın mod değeridir. Eleman sayısı 30'dan küçük olan örneklemler için $a$ ve $x_{0}$ değerleri sırasıyla denklem 14 ve 15 ile bulunur.

$$
\begin{gathered}
a=\frac{\sigma_{n}}{\sigma_{x}} \\
x_{0}=\bar{x}-y_{n} \frac{\sigma_{x}}{\sigma_{n}}
\end{gathered}
$$

Burada; $y_{n}$ ve $\sigma_{n}$ sabit değerler, $\bar{x}$ gözlenmiş değerlerin ortalaması, $\sigma_{x}$ ise standart sapmasıdır [10]. 


\subsection{Pearson Tip III Dağılımı}

Olasılık yoğunluk fonksiyonu denklem 16'da verilen Pearson Tip 3 dağılımının eklenik yoğunluk fonsiyonu elde edilememektedir. $\mathrm{Bu}$ dağılımın parametre tahmini, momentler ya da maksimum olabilirlik yöntemleri ile yapılabilir.

$f(x)=\frac{1}{\beta^{\alpha} \Gamma(\alpha)}\left(x-x_{0}\right)^{\alpha-1} e^{\frac{-\left(x-x_{0}\right)}{\beta}}$

Momentler yöntemi ile ortalama $(\bar{x})$, standart sapma $\left(s_{x}\right)$, çarpıklık katsayısı $\left(C_{s x}\right)$ ile dağılımın $\alpha, \quad \beta$ ve $x_{0}$ parametreleri arasındaki ilişkiler denklem 17, 18 ve 19 ile bulunurlar [11].

$$
\begin{gathered}
\bar{x}=x_{0}+\alpha \beta \\
s_{x}^{2}=\alpha \beta^{2} \\
C_{s x}=\frac{2}{\sqrt{\alpha}}
\end{gathered}
$$

\subsection{Log-Pearson Tip III Dağılımı}

Taşkın analizlerinde çok sık kullanılan dağılım tipidir. Kullanım yönünden log-normal dağılıma benzemektedir. Değişkenlerin 10 ya da $e$ tabanlı logaritmaları alınarak dağılıma ait aşağıda verilen parametreler bulunur (denklem 20, 21 ve 22).

$$
\begin{gathered}
\mu_{\log x}=\frac{\sum \log x}{n} \\
\mathrm{~S}_{\log \mathrm{x}}=\sqrt{\frac{\sum\left(\log x-\mu_{\log x}\right)^{2}}{n-1}}
\end{gathered}
$$

$$
\mathrm{G}=\frac{\mathrm{n} \sum\left(\log \mathrm{x}-\mu_{\log \mathrm{x}}\right)^{3}}{(\mathrm{n}-1)(\mathrm{n}-2)\left(\mathrm{s}_{\log \mathrm{x}}\right)^{3}}
$$

Burada, $\mu_{\log x}$ logaritmaların ortalamas1, $S_{\log x}$ logaritmaların standart sapması, $G$ çarpıklık katsayısı ve $n$ değişken sayısıdır.

Belli bir yineleme dönemine ait $x$ değeri denklem 23'e göre bulunur.

$$
\log x=\mu_{\log x}+\mathrm{Ks}_{\log x}
$$

Buradaki K değeri, frekans faktörüdür ve çarpıklık katsayıs1 ile yineleme döneminin bir fonksiyonudur [10].

\subsection{Kolmogorov - Smirnov (K-S) Testi}

Kolmogorov-Smirnov testi ile gözlenen verilerin herhangi bir dağılıma uygun olup olmadığ edilmektedir. $\mathrm{Bu}$ test ile çekilen örneğin, sözü edilen dağılıma sahip ana kitleden gelip gelmediğini araştırmak için beklenen dağılımın altında geçerli olan kümülatif frekans dağılımını gözlenen frekans dağılımı ile karşılaştırmak gerekmektedir. $\mathrm{Bu}$ karşılaştırma sırasında iki kümülatif dağılım arasında en büyük sapma, en büyük mutlak fark olarak belirlenir. Daha sonra örnek dağglımına göre bu ölçüdeki farkın şans eseri elde edilip edilmeyeceği araştırılır [12].

$$
D_{\max _{i}}=\left|F\left(x_{i}\right)-F^{*}\left(x_{i}\right)\right|
$$

Burada $F\left(x_{i}\right)$ seçilen dağılım fonksiyonun aynı $x_{i}$ 'lere karşı1lk gelen ordinatları, $F^{*}\left(x_{i}\right)$ ise gözlenen örnekten hesaplanan eklenik frekans dağılımı ordinatıdır. $F^{*}\left(x_{i}\right)$ denklem 25 ile hesaplanir.

$$
F^{*}\left(x_{i}\right)=\frac{i}{N}
$$

$D$ istatistiği gözlenen ve teorik eklenik dağılımların arasındaki farkların en büyüğüdür. $D$ istatistiğinin dağılımı rastgele değişkenin dağılımından bağımsız olup sadece örnekteki $N$ eleman sayısına bağlıdır [11].

\section{3. ÇALISMA BÖLGESI VE VERILER}

Aksu Çayı, Isparta ili yakınlarındaki Akdağ ve Davraz Dağı'ndan doğar. Aksu Çayı, güneydoğu yönünde ilerleyerek Kovada Gölü'nde yer altı sularıyla karışarak aşağı Gökdere Köyü'nün güneyinde Eğirdir Gölü'nden gelen sularla birleşerek güneye doğru akar. Burada Göksu ile birleşerek Antalya Körfezi'nden denize dökülür. Aksu Çayı havzası 36-38 kuzey enlemleri ile 3031 doğu boylamları arasında yer almaktadır. Aksu Çayı havzasının su toplama alanı $8000 \mathrm{~km}^{2}$ dir. Kalker katmanlarda bol miktarda su veren birçok karstik kaynaklar ırmağı besler. Su düzeyi yaz ve 
sonbahar aylarında düşmesine rağmen vadide her zaman bol su vardır. Kış ve ilkbahar aylarında sağanaklar ve kar erimeleriyle akarsuyun debisi artmaktadır. Aksu Çayı aşağı kesiminde düzlüklerde akmakta ve sulamada bol miktarda kullanılmaktadır. Aksu Çayı havzasını drene eden akarsular da değişik drenaj tiplerine sahiptir ve özellikle Aksu Çayı aşağı vadisinde örgülü drenaj tipine sıkça rastlanmaktadır [13]. Çalışma alanı olarak seçilen Küçük Aksu Çayı, Aksu Çayı'nın yan kollarından biridir (Şekil 1).

Bu çalışmada Küçük Aksu üzerinde havza çıkış noktasına yaklaşı $8 \mathrm{~km}$ uzaklıkta bulunan DSİ'nin işletmiş olduğu 9-34 no.lu akım gözlem istasyonuna (AGI) ait 1998-2014 y1lları arasında bulunan yıllık maksimum akım değerleri kullanılmıştır.

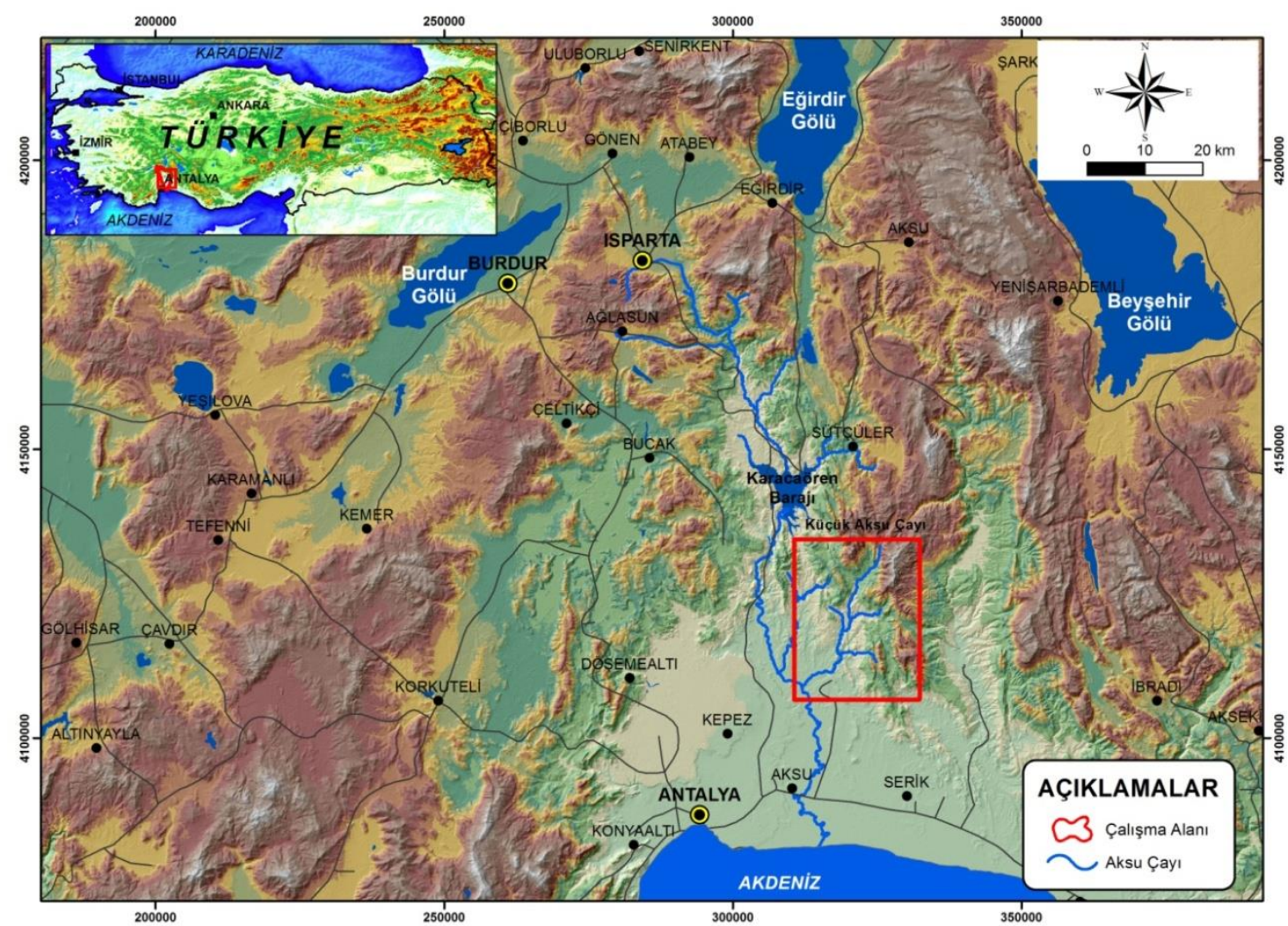

Şekil 1. Çalışma alanı yerbulduru haritası.

\section{BULGULAR}

Çalışma bölgesi içerisinde bulunan Küçük Aksu Çayı'na ait 2, 5, 10, 25, 50, 100, 200, 500 ve 1000 yıl gibi farklı tekerrrür dönemlerine ait taşkın debileri tahmin edilmiştir. $\mathrm{Bu}$ debiler belirlenirken, yıllık maksimum akımlara farklı olasılık dağılım fonksiyonları olan üç paremetreli log-normal, Gumbel, Pearson Tip III ve LogPearson Tip III dağılımları uygulanmıştır. En uygun dağ 1 lımın belirlenmesinde KolmogorovSmirnov testi ve grafiksel yöntemlerden yararlanılmıştır.
$\ddot{U}_{c} \quad$ Parametreli Log-Normal Dă̆llım: Denklemlerde gerekli olan değerler, $\mathrm{Cs}=0.26$; $\mathrm{c}=0.23 ; \mathrm{d}=0.89 ; \mathrm{f}=0.08 ; \mathrm{a}=0.01$ alınarak 100 yıllık taşkın debisi için hesaplanırsa $z=2.32635$ elde edilir. Değerler formülde yerlerine yerleştirildiğinde ise, $\quad Q_{100}=178.05 \mathrm{~m}^{3} / \mathrm{s}$ çıkmıştır.

Gumbel Dăğllımı: $\mathrm{N}=17$ 'ye göre $\mathrm{y}_{\mathrm{n}}=0.5181$ ve $\sigma_{\mathrm{n}}=1.0411$ 'dir. Ortalamas1 ( $\left.\bar{x}\right) 69.48$, standart sapmas1 $\left(s_{x}\right) 43.43, a$ değeri 41.72 ve $\mathrm{x}_{0}$ değeri 47.86 olarak bulunmuştur. Denklem 12 ve 13 ortak çözümünden $\mathrm{Q}_{100}=239.78 \mathrm{~m}^{3} / \mathrm{s}$ olarak hesaplanmıştır. 
Pearson Tip III Dă̆glımı: Akım değerlerinin denklem 17 'den ortalaması $(\bar{x}) 69.48$, denklem 18 'den standart sapması $\left(s_{x}\right) 43.43$ ve denklem 19'dan çarpıklık katsayıları $\left(C_{s x}\right) 0.26$ olarak belirlenmiştir. 100 yıllık taşkın debisi 178.64 $\mathrm{m}^{3} / \mathrm{sn}$ olarak bulunmuştur.

Log-Pearson Tip III Dağılımı: 10 tabanında logaritmaları hesaplanan akım değerlerinin denklem 20 'den ortalaması $\left(\mu_{\log x}\right) 1.73$, denklem
21 'den standart sapmas1 $\left(\mathrm{s}_{\operatorname{logx}}\right) \quad 0.34$ ve denklem 22'den çarpıklık katsayıları (G) -0.65 olarak belirlenmiştir. 100 yıllık taşkın debisi denklem 23'de belirtildiği şekilde hesaplanarak 236.14 $\mathrm{m}^{3} / \mathrm{sn}$ olarak bulunmuştur. Çizelge 1'de farklı olasılık dağılımları ve tekerrür dönemlerine ait belirlenen taşkın debileri verilmiştir.

Çizelge 1. Farklı dağılımlara ait taşkın frekans analiz sonuçları.

\begin{tabular}{ccccc}
\hline \multirow{2}{*}{$\begin{array}{c}\text { Tekerrür } \\
\text { Periyotları }\end{array}$} & $\begin{array}{c}\text { Üç Parametreli } \\
\text { Log-Normal } \\
\left.\text { Dağılım (m }{ }^{3} / \mathrm{s}\right)\end{array}$ & $\begin{array}{c}\text { Gumbel } \\
\text { Dağılımı } \\
\left(\mathrm{m}^{3} / \mathrm{s}\right)\end{array}$ & $\begin{array}{c}\text { Pearson } \\
\text { Tip III Dă̆llımı } \\
\left(\mathrm{m}^{3} / \mathrm{s}\right)\end{array}$ & $\begin{array}{c}\text { Log-Pearson } \\
\text { Tip III } \\
\text { Dağılımı }\end{array}$ \\
\hline $\left.\mathbf{Q}^{3} / \mathrm{s}\right)$
\end{tabular}

Kolmogorov-Smirnov Testi: Farkl1 olasıl1k dağılımları ile taşkın tahminlerinin ardından en uygun dağılımın belirlenmesi gerekmektedir. Bunun için Kolmogorov-Smirnov testinden yararlanılmıştır. Kolmogorov-Smirnov testi gözlenen ve beklenen değerlerin kümülatif nisbi frekansları arasındaki mutlak farkın en büyüğüdür. Her bir dağılım için denklem 25 ile beklenen frekanslar ve denklem 24 ile her bir dağılım için test istatistiği hesaplanmıştır. Yapılan hesaplamalar Çizelge 2'de verilmiştir.

Çizelge 2. Küçük Aksu Çayı için K-S testi sonuçları.

\begin{tabular}{lccc}
\hline \multicolumn{1}{c}{ Dağılım Tipi } & \multirow{2}{*}{ D $_{\max }$} & Anlamlılık Yüzdeleri \\
& & $\mathbf{0 . 9 0}$ & $\mathbf{0 . 9 5}$ \\
\hline Üç Parametreli Log-Normal & 0.115 & Kabul & Kabul \\
Gumbel & 0.104 & Kabul & Kabul \\
Pearson Tip III & 0.119 & Kabul & Kabul \\
Log-Pearson Tip III & 0.099 & Kabul & Kabul \\
\hline
\end{tabular}

Çizelge 2 incelendiğinde kullanılan tüm dağılımların Küçük Aksu Çayı taşkın tahmininde uygun olduğu görülmüştür. Ancak $\mathrm{D}_{\max }$ değerleri dikkate alındığında Kolmogorov-Smirnov testine göre en uygun dağılımın Log-Pearson Tip III dağılımı olduğu belirlenmiştir. Sonuçları desteklemek için grafik olarak dağılımın LogPearson Tip III'e uyduğu Şekil $2,3,4$ ve 5 incelendiğinde görülmüştür. 


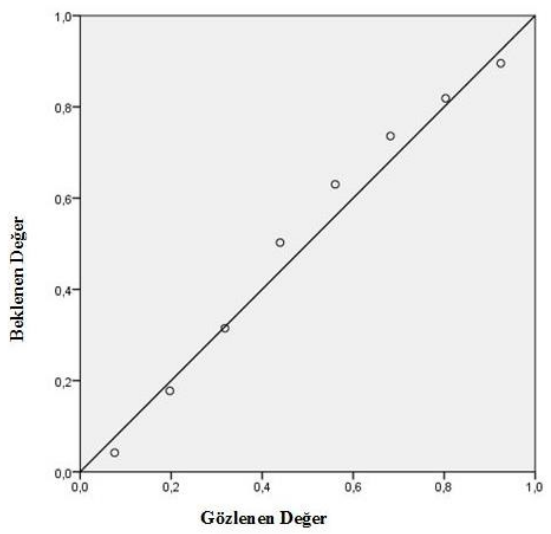

Şekil 2. Üç Parametreli Log-Normal Dağılım P-P grafiği.

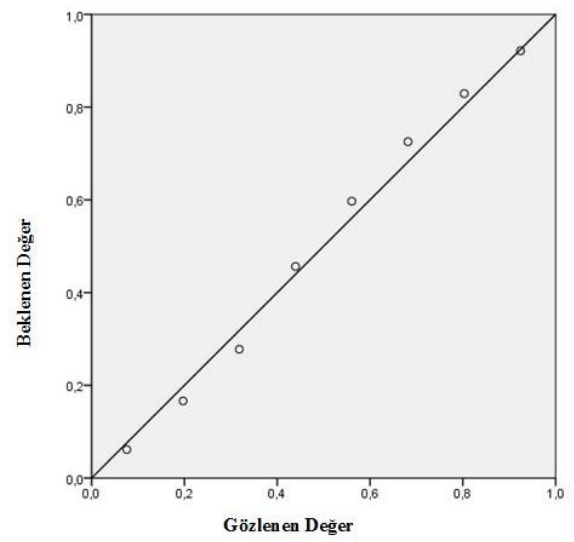

Şekil 3. Gumbel Dağılımı P-P grafiği.

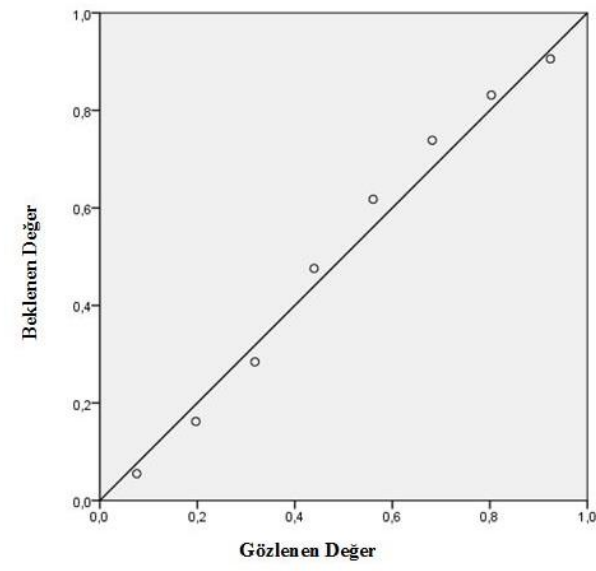

Şekil 4. Log-Pearson Tip III Dağılım P-P grafiği.

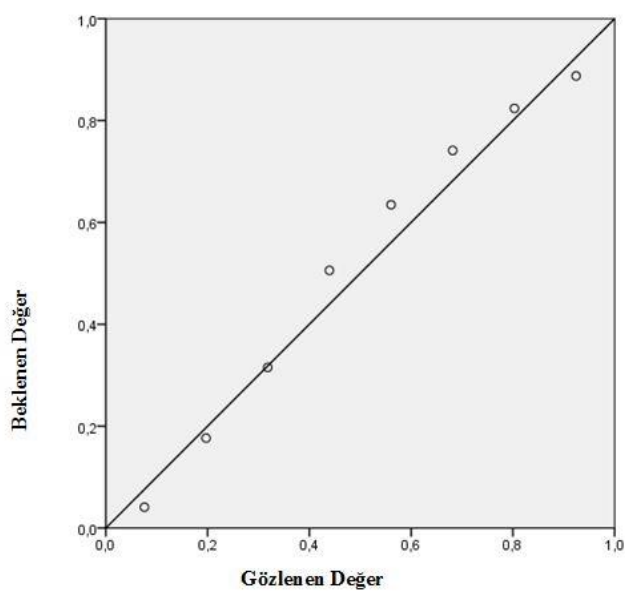

Şekil 5. Pearson Tip III Dağılım P-P grafiği.

\section{TARTIŞMA VE SONUÇLAR}

Taşkın debilerinin doğru tahmini su kaynakları yönetimi, taşkın koruma ve hidrolik yapılar için oldukça önemlidir. Gereğinden büyük tahminler havzada yapılacak olan projelerin maliyetini arttırmakta, gereğinden küçük yapılan tahminler ise can ve mal kaybı riskini arttırmaktadır. Bundan dolayı taşkın frekans analizlerinde hangi dağılımın akım verilerine uygun olduğunun belirlenmesi ve tahminlerin değerlendirmesi gerekmektedir.

Üç parametreli log-normal, Gumbel, Pearson Tip III ve Log-Pearson Tip III dağılımları ile taşkın frekansları hesaplanmıştır. Küçük Aksu Çayı üzerinde gözlemlenen yıllık maksimum akımlar öncelikle olasılık dağılım fonksiyonları ile modellenmiştir. Daha sonra olasılık dağılım sonuçları grafiksel sınama ve KolmogorovSmirnov testi ile sınanmış, sınama sonucunda en uygun dağılımın Log-Pearson Tip III olduğu belirlenmiştir.

\section{TEŞEKKÜR}

$\mathrm{Bu}$ çalışma, Süleyman Demirel Üniversitesi Bilimsel Araştırma Projeleri (BAP) birimi tarafından desteklenmiş olan 4236-YL1-14 no'lu "Coğrafi Bilgi Sistemleri Tabanlı Hidrolik Model ve Çok Kriterli Karar Verme Analizi ile Taşkın Risk Analizi: Küçük Aksu Çayı Örneği” konulu proje kapsamında yapılmıştır. 


\section{KAYNAKLAR}

[1]. Özcan O. Sakarya Nehri Alt Havzası'nın Taşkın Riski Analizinin Uzaktan Algılama ve CBS ile Belirlenmesi. İstanbul Teknik Üniversitesi, Bilişim Enstitüsü, Yüksek Lisans Tezi, 62s, İstanbul 2007.

[2]. Seçkin N., Yurtal R. L-Momentlere Dayalı Gösterge-Sel Metodu İle Bölgesel Taşkın Frekans Analizi. Ç.Ü Fen Bilimleri Enstitüsü, 2008. Cilt:19-4

[3]. Anl1 A.S. "Giresun Aksu Havzas1 Maksimum Akımlarının Frekans Analizi." Akdeniz Üniversitesi Ziraat Fakültesi Dergisi, 2006.19(1), 99-106.

[4]. Aşık Ş., Akkuzu E., Karataş B.S., Gediz Havzası Akarsuları Yıllık Toplam Akımlarına En Uygun Olasılık Dağılım Modelinin Belirlenmesi. Ege Üniversitesi Ziraat Fakültesi Dergisi, 2004; 41: (3):177184.

[5]. Büyükkaracığan N., Kahya E. Konya Havzası Akarsuları Y1llı Pik Akım Serilerinin Taşkın Frekans Analizi. SelçukTeknik Dergisi, 2009.Cilt 8, Sayı:3.

[6]. Saka F., Yüksek Ö., Yıldırım M.S., Baş K., Anılan T., Kaplan H. "Yillık Maksimum Akımların Bazı Olasılık Dağılımlarına Uygunluğunun Ki-Kare Ve KolmogorovSmirnov Testleriyle Belirlenmesi.” Taşkın ve Heyelan Sempozyumu, 24-26 Ekim 2013, Trabzon, 2013. 339-348.

[7]. Yüksek Ö., Anılan T., Serencam U., Ertaş B. "Doğu Karadeniz 'deki şiddetli Yağışlar ve Taşkın Debilerine Uyan Dağılımların Analizi." Taşkın ve Heyelan Sempozyumu, 24-26 Ekim 2013, Trabzon 2013., 377-381.

[8]. Bayazıt M., "Hidrolojik Modeller." Teknik Üniversite Matbaası. 228 s, İstanbul. 1998.

[9]. Usul N., "Mühendislik Hidrolojisi." ODTÜ Yayınc1lık. 418 s, Ankara. 2008.

[10]. Bayazıt M. "Hidroloji." Birsen Yayınevi. 219 s, İstanbul. 2003

[11]. Uçar İ. "Trabzon Değirmendere Havzası'nda Coğrafi Bilgi Sistemleri ve Bir Hidrolik Model Yardımıyla Taşkın Analizi Yapılmas1." Gazi Üniversitesi, Fen Bilimleri Enstitüsü, Yüksek Lisans Tezi, 158s, Ankara. 2010.

[12]. Bayazıt M., Önöz B. "Taşkın ve Kuraklık Hidrolojisi." Nobel Yayın Dağıtım. 259 s. Ankara. 2008.

[13]. Çakıc1 M., Oğuzhan A., Özdil T. "İstatistik." Ekin Basın Yayın Dağıtım. 383 s. Bursa. 2015.

[14]. Anonim, 2014. "Aksu Çayı.” Erişim Tarihi: 10.09.2014.

http://tr.wikipedia.org/wiki/Aksu_\%C3\%87 ay\% $4 \%$ B 1 